\title{
Penerapan Prinsip Ergonomi Untuk Perancangan Fasilitas Duduk Dari Material Bambu Laminasi Sistem Cold Press Dua Arah
}

\author{
Hari Nugraha $^{1}$, Taufiq Panji Wisesa ${ }^{2}$, Ismail Alif Siregar ${ }^{3}$, \\ ${ }^{1}$ Program Studi Desain Produk, Universitas Pembangunan Jaya \\ hari.nugraha@upj.ac.id \\ ${ }^{2}$ Program Studi Desain Produk, Universitas Pembangunan Jaya \\ panji.wisesa@upj.ac.id \\ ${ }^{3}$ Program Studi Desain Produk, Universitas Pembangunan Jaya \\ ismail.alif@upj.ac.id
}

\begin{abstract}
Bamboo materials have many practical uses; one of them is to make functional furniture such as chairs. Traditionally, the way to make furniture out of bamboo is to use cylindrical bamboo that is cutting and assembled into the shape of a chair. This traditional way of making chairs out of bamboo results in a product that is looks rigid, massive and it is not ergonomically ideal. An alternative way to produce the chair is by using the bamboo bending method. In this way, a more dynamic shape can achieve by using the cold press laminated technique to bend the bamboo. In this method, the bamboo is cutting into thin strips, pressed, and laminates. To make the bend, a two-way press is used. By using the mould, the bamboo shaped into a more ergonomic shape, which suits a more anthropometrical model. From a product design point of view, the use of this method fulfils the ergonomic principles of a chair and can used to make other creative and innovative products.
\end{abstract}

Keyword: Bamboo, Laminated, Ergonomic, Antropometric, Design, Furniture

Abstrak: Material Bambu memiliki banyak kegunaan untuk kebutuhan praktis, salah satunya adalah untuk pembuatan produk furnitur seperti kursi. Secara tradisional, cara pembuatan furnitur dari bambu yaitu dengan memanfaatkan bambu yang berbentuk silindris kemudian dipotong dan dirangkai menjadi bentuk kursi. Cara tradisional tersebut, menghasilkan produk yang terlihat kaku, masif dan kurang ergonomis. Salah satu alternatif untuk memproduksi furniture dari material bambu adalah dengan menggunakan metode bending (tekuk), cara tersebut dapat menghasilkan bentuk furniture yang ergonomis. Proses bending bambu dilakukan dengan menggunakan teknik laminasi cold press (press dingin) yaitu, batang bambu dipotong menjadi lembaran-lembaran tipis, selanjutnya dilakukan proses laminasi dengan menggunakan sistem cetakan dua arah. Dengan menggunakan cara tersebut, material bambu dapat diolah dengan bentuk yang ergonomis, menyesuaikan dengan setandar antropometrik penggunanya. Dari sudut pandang desain produk, penggunaan metode ini dapat memenuhi prinsip-prinsip ergonomis untuk produk kursi dan dapat digunakan untuk membuat produk kreatif dan inovatif lainnya.

Kata Kunci: Bambu, Laminasi, Ergonomi, Antropometri, Desain, Furniture

\section{PENDAHULUAN}

Pemanfaatan material bambu yang diolah dengan cara laminasi, ditinjau dari aspek kekuatan dan kelenturan material, sangat layak digunakan untuk produk furniture. Pemanfaatan material bambu untuk pembuatan produk furniture seperti untuk sarana duduk (kursi) yang diproduksi oleh pengrajin produk furniture bambu sekala usaha kecil menegah (UKM) umumnya masih menerapkan cara pengolahan yang konvensional, sederhana dan desain dari produk tersebut tidak banyak mengalami perubahan bentuk.

Kursi bambu tradisional yang dibuat oleh pengrajin UKM lokal, dibuat dari potongan-potongan batang bambu yang disatukan dan dirakit dengan menggunakan anyaman dari kulit rotan atau serat tali alami lainnya. 
Penelitian yang dilakukan ini, fokus untuk membahas mengenai desain ulang kursi bambu yang dibuat dan dibentuk dengan menggunakan sistem laminasi cold press dengan desain yang mempertimbangkan aspek antropometri dan ergonomi yang berkaitan langsung dengan penggunanya.

Sistem cetakan laminasi cold press dua arah digunakan untuk membentuk dan menghasilkan bentuk penampang material bambu yang dapat dibentuk dengan arah lengkungan yang berbeda (horizontal dan vertikal). Dengan pola arah lengkungan dua arah tersebut, bentuk akhir laminasi material bambu dapat dibentuk menyesuaikan dengan bentuk tubuh dari postur penggunanya.

Hasil dari pengolahan material bambu ini, diharapkan dapat menghasilkan desain produk yang kreatif, inovatif, estetik dan dapat meningkatkan nilai jual produk serta dapat diterapkan secara langsung oleh indutri dan pengrajin produk furniture bambu sekala kecil dan menegah khususnya untuk wilayah Tangerang Selatan.

\section{TUJUAN PENELITIAN}

Tujuan khusus dari penelitian ini yaitu menerapkan standar ergonomi dan atropometri untuk produk fungsional yang dibuat dari material dasar bambu laminasi, yang dibentuk dengan menggunakan sistem cold press dua arah. Produk yang akan dijadikan sebagai studi kasus dalam penelitian ini yaitu produk kursi yang dibuat dari material bamboo laminasi.

Tujuan umum dalam penelitian ini yaitu sebagai salah satu bentuk penerapan dan pengembangan keilmuan dalam bidang ergonomi dan antropometri untuk desain produk. Tujuan akhir dari hasil penelitian ini diharapkan dapat diterapkan secara praktis untuk pembuatan produk dari material bambu dengan desain yang inovatif, selain itu dengan pelaksanaan penelitian ini, diharapkan dapat digunakan oleh lingkungan akademis maupun untuk masyarakat sekitar terutama untuk industri kecil pembuatan produk dari material bambu.

\section{KAJIAN PUSTAKA}

Penelitian terdahulu yang telah dilakukan dalam bidang ergonomi dan antropometri untuk kursi bambu yaitu, penelitian yang dilakukan oleh Wignjosoebroto (2007). Hasil penelitian tersebut menyatakan bahwa, kursi bambu yang dibuat secara tradisional oleh pengrajin jika digunakan untuk bersandar dalam jangka waktu pendek dan lama tidak nyaman. Rata-rata sudut sandaran kursi bambu tradisional tegak lurus 90 derajat.

Dalam pembuatan kursi bambu, disarankan ditambahkan sandaran tangan untuk meningkatkan kenyamanan pengguna dan dapat membantu pengguna pada saat posisi akan berdiri maupun pada saat duduk. Penelitian yang dilakukan oleh Wignjosoebroto tersebut bertujuan untuk menganalisa produk kursi bambu yang telah ada sebelumnya berdasarkan pengukuran antropemetrik penggunaanya dan kemudian melakukan modifikasi desain.

Hasil modifikasi dari kursi bambu, kemudian dievaluasi dengan cara membandingkan produk lama-tradisional dengan prototype produk hasil modifikasi. Kesimpulan akhir dari penelitian tersebut menunjukkan bahwa hasil prototype modifikasi kursi bambu lebih ergonomis.

Berikut ini tabel data antropometri hasil analisa penelitian yang dilakukan oleh Wignjosoebroto:

Tabel 1. Tabel data antropometri hasil analisa Wignjosoebroto

\begin{tabular}{|l|l|c|}
\hline \multicolumn{1}{|c|}{ Ukuran } & \multicolumn{1}{c|}{ Dimensi } & $\begin{array}{c}\text { Hasil } \\
\text { Perhitungan } \\
(\mathrm{cm})\end{array}$ \\
\hline Tinggi alas duduk & Tinggi popliteal duduk & 35 \\
\hline Lebar alas duduk & Lebar pinggul duduk & 44 \\
\hline Panjang alas duduk & Jarak pantat-popliteal & 45 \\
\hline Tinggi sandaran & Tinggi bahu duduk & 53 \\
\hline Lebar sandaran punggung & Lebar bahu duduk & 41 \\
\hline Sudut sandaran punggung & Derajat kemiringan & $105^{\circ}$ \\
\hline Tinggi sandaran tangan & Tinggi siku duduk & 25 \\
\hline Panjang sandaran tangan & Panjang lengan bawah & 55,5 \\
\hline
\end{tabular}

vasar penggunaan materiaı bambu

laminasi sebagai material yang dapat 
digunakan untuk pembuatan produk kursi, dapat merujuk kepada hasil penelitian mengenai kekuatan dan kelenturan bambu laminasi yang dilakukan oleh Gusti made oka (Jurnal SMARTek, Vol. 6, No. 2, Mei 2008), penelitian tersebut menguji kekuatan balok laminasi sistem vertikal dan horizontal. Bambu laminas yang diuji menggunakan bahan perekat thermoset jenis urea formaldehyde yang dalam proses laminasinya menggunakan proses cold pressing.

Bambu laminasi yang diuji yaitu meliputi:

1. Uji kerapatan dan kadar air.

2. Kuat tekan sejajar serat, kuat tekan tegak lurus serat dan kuat tarik sejajar serat.

3. Kuat lentur, modulus elastisitas dan geser sejajar serat.

Hasil pengujian Gusti made oka. (2008: 102) mengatakan bahwa berdasarkan hasil pengujian kekuatan balok laminasi vertikal dan horizontal dengan besarnya pengempaan 75 memberikan kekuatan lentur yang optimum baik balok laminasi horizontal $(63,58 \mathrm{MPa})$ maupun vertikal $(82,65 \mathrm{MPa})$, sehingga rasio kekuatan balok laminasi horisontal dan vertikal terhadap perilaku lentur $1: 1,3$.

Tabel 2. Tabel hasil uji rasio kekuatan balok laminasi vertikal dan horizontal Jurnal SMARTek, Vol. 6, No. 2, Mei 2008

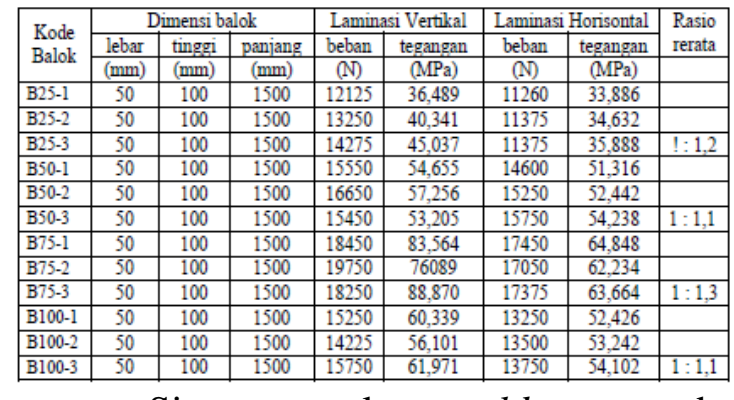

Sistem cetakan cold press dan bending yang digunakan untuk membentuk komponen kursi bambu laminasi menggunakan teknik yang dipakai untuk membentuk kayu laminasi, yaitu menggunakan teknik cetakan satu arah dan cetakan dua arah. Dari sistem yang digunakan untuk proses pres dan bending kayu laminasi tersebut, kemudian dimodifikasi untuk dapat digunakan pada material bambu laminasi dengan bidang permukaan yang lebar.

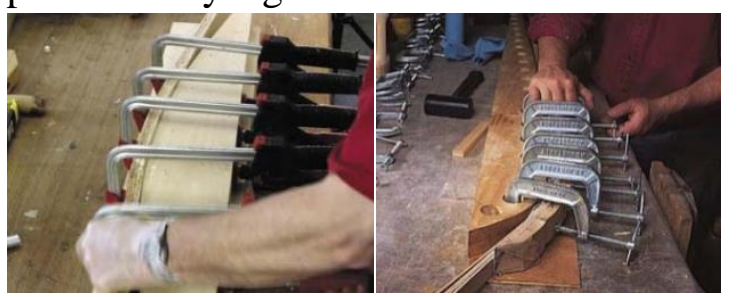

Gambar 1. Proses pres dan bending satu arah untuk material kayu

Essential Techniques for Bending Wood, Popular Woodworking October 2005.

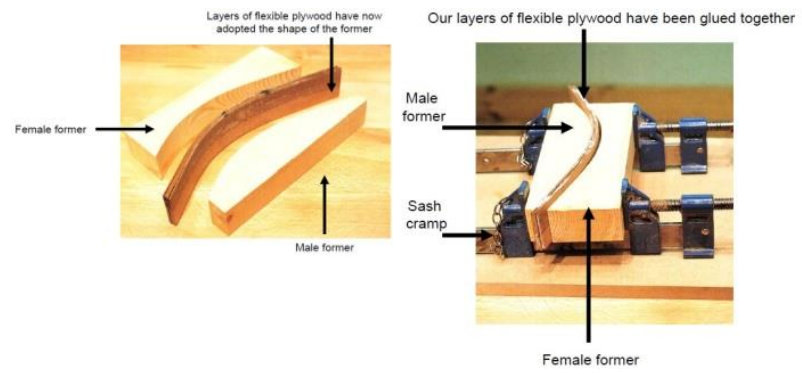

Gambar 2. Proses pres dan bending sistem dua arah untuk material kayu

Essential Techniques for Bending Wood, Popular Woodworking October 2005.

Untuk pembuatan komponen dari kursi bambu laminasi yang memiliki ukuran lebar penampang sekitar $40 \mathrm{~cm}-$ $50 \mathrm{~cm}$, menggunakan cetakan sistem dua arah yang umumnya digunakan untuk material kayu. Agar dapat digunakan untuk material bambu laminasi, cetakan tersebut dimodifikasi agar dapat melakukan proses pres pada permukaan yang lebar, modifikasi yang dilakukan yaitu dengan membuat desain cetakan yang disusun dari beberapa rangka cetakan yang dapat menekan permukaan material bambu laminasi yang memiliki penampang lebar.

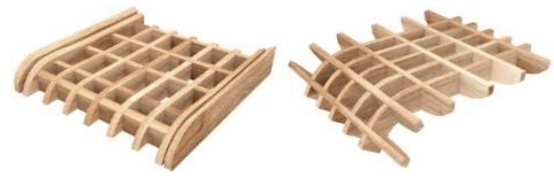

Gambar 3. Desain cetakan dua arah untuk Proses pres dan bending bambu laminasi.

\section{METODOLOGI PENELITIAN}

Metode penelitian yang akan dilakukan yaitu dengan cara kuantitatif dan 
kualitatif melalui proses eksperimen pembuatan laminasi bambu cold press. Proses eksperimen yang dilakukan yaitu meliputi eksperimen pembuatan laminasi untuk rangka dan struktur utama kursi, pembuatan cetakan cold press sistem dua arah untuk membentuk komponen sandaran dan alas duduk kursi.

Metode lain yang akan dilakukan yaitu menguji kekuatan komponen rangka, sandaran punggung dan alas duduk untuk menahan beban dengan cara melakukan uji coba secara langsung kepada pengguna kursi tersebut. Hasil dari pengujian tersebut akan digunakan untuk melakukan revisi dari desain prototype kursi bambu laminasi yang telah dibuat sebelumnya agar dapat memenuhi kelayakan penggunaan dari aspek ergonomi dan antropometri penggunanya. Gambar 4 menunjukkan diagram tahapan yang akan dilakukan untuk proses eksperimen, pembuatan prototype kursi.

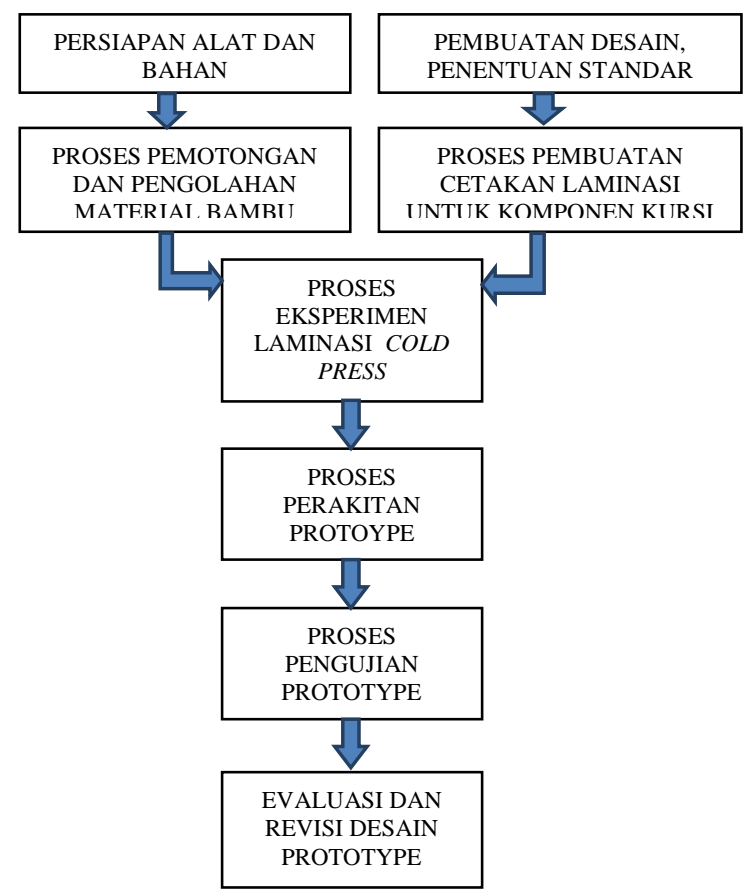

Gambar 4. Proses eksperimen pembuatan prototype kursi

\section{HASIL PENELITIAN}

Proses Pembuatan Cetakan dan Prototype Kursi Bambu Laminasi.
Tahap awal yang dilakukan dalam penelitian ini yaitu menentukan dan membuat desain awal dari kursi bambu yang akan dibuat dengan cara cold press dengan bahan perekat yang dipakai yaitu jenis thermoset urea formaldehyde dan epoxy resin.

Kursi bambu tersebut didesain menggunakan sistem dowel (pasak) untuk perakitan setiap komponen kursi dan diperkuat dengan menggunakan perekat epoxy resin. Komponen kursi bambu laminasi yang didesain terdiri dari 2 komponen utama yaitu alas duduk dan sandaran duduk dan 2 komponen pendukung yaitu komponen struktur kursi dan rangka sandaran kursi. Karena keterbatasan fungsi cetakan laminasi yang dibuat dengan menggunakan bahan multiplek dengan tebal $15 \mathrm{~mm}$ dengan sistem pres manual untuk proses pres cetakan, menyebabkan desain awal dari kursi bambu yang dibuat harus mengalami penyederhanaan bentuk. Gambar 5 memperlihatkan desain awal hasil penyederhanaan bentuk dari kursi bambu laminasi yang akan dibuat:

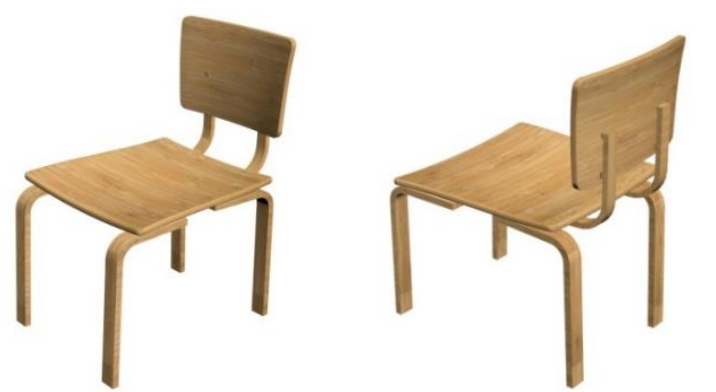

Tampak 3d depan Tampak 3d belakang Gambar 5. Desain awal kursi bambu laminasi hasil penyederhanaan bentuk.
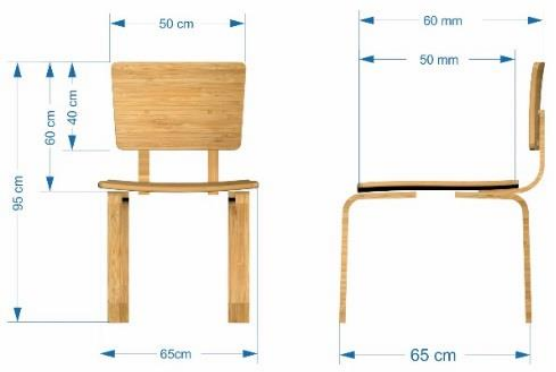

Tampak depan Tampak samping Gambar 6. Gambar dimensi kursi bambu. 


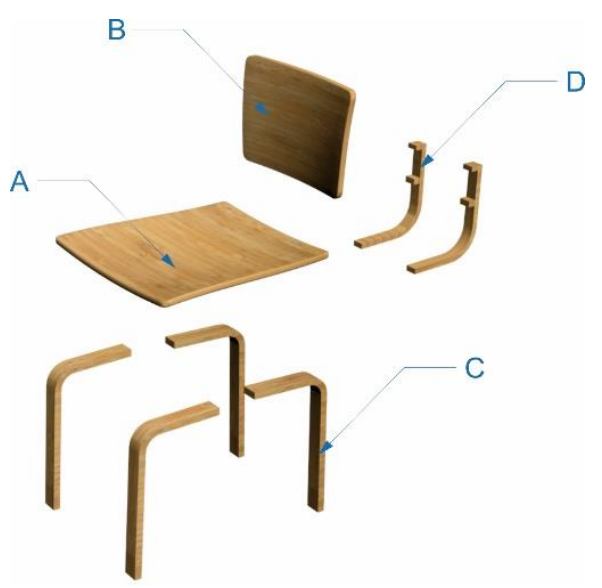

Gambar 7. Gambar uraian komponen kursi bambu.

Berikut informasi keterangan gambar 7:

A. Komponen alas duduk

B. Komponen sandaran duduk

C. Komponen rangka kaki

D. Komponen rangka sandaran duduk

Untuk menghasilkan bentuk desain alas duduk dan sandaran kursi yang mendekati dengan desain awal yang telah dibuat sebelumnya, cetakan pres yang dibuat harus dapat membentuk dan menekan permukaan penampang lembaran bambu laminasi dari dua arah titik pres yang berbeda.

Tahap awal pembuatan komponen kursi bambu yaitu dimulai dengan pembuatan cetakan pres dan dilanjutkan dengan proses pembuatan komponen sandaran duduk. Cetakan pres laminasi dibuat dengan cara sederhana dari material multiplek dengan ketebal $15 \mathrm{~mm}$, alat bantu lainnya yang digunakan untuk melakukan proses pres yaitu dengan menggunakan alat klem manual.

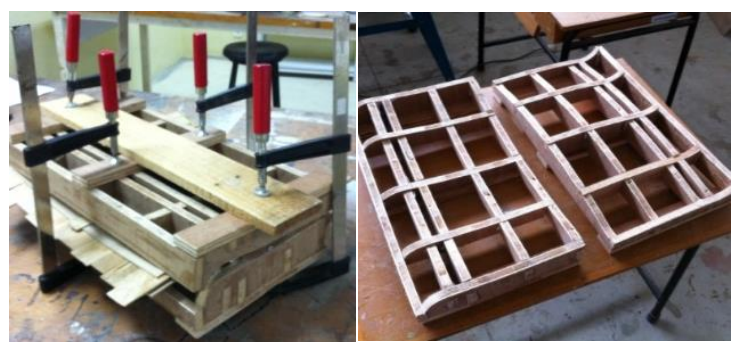

Gambar 8. Proses pres untuk pembuatan komponen sandaran duduk kursi bambu laminasi.

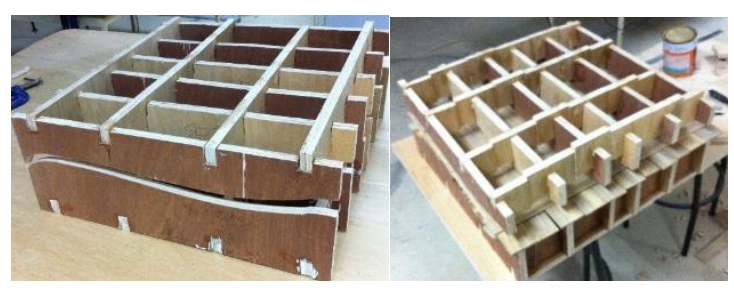

Gambar 9. Cetakan laminasi komponen alas duduk dan roses pres untuk pembuatan komponen.

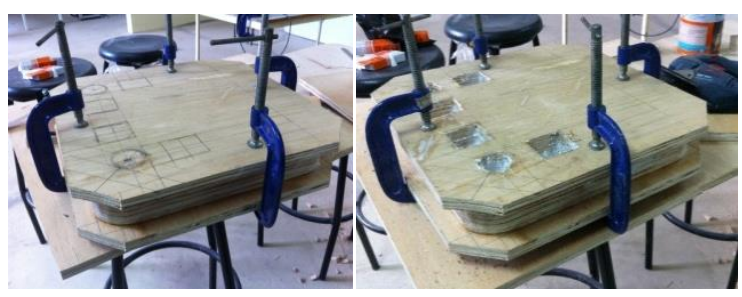

Gambar 10. Cetakan untuk pembuatan komponen struktur rangka kursi bambu laminasi

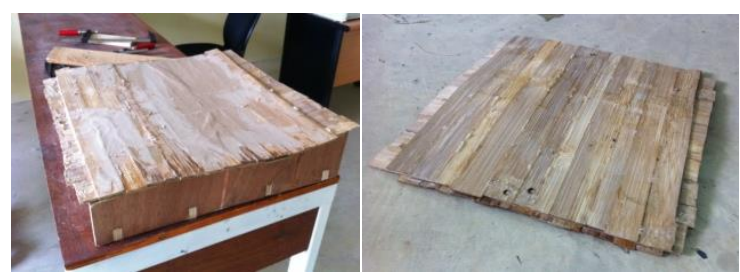

Gambar 11. Hasil proses pres untuk pembuatan komponen alas duduk.

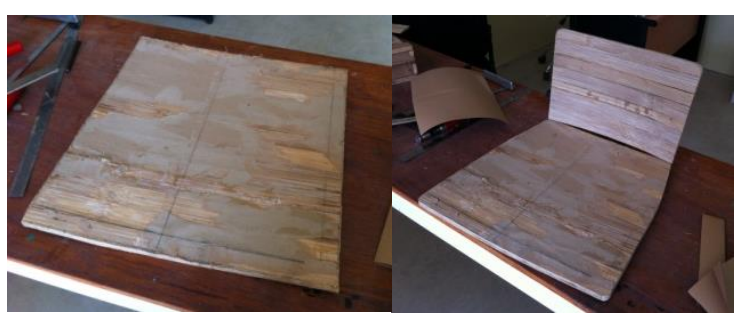

Gambar 12. Komponen alas duduk dan sandaran kursi yang telah dibentuk dan dihaluskan.

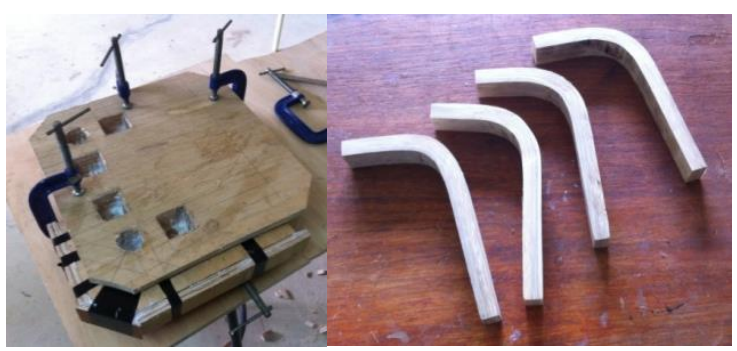

Gambar 13. Proses pres untuk komponen rangka kaki kursi dan komponen hasil pres.

Setelah komponen kursi bambu laminasi selesai dibuat, proses selanjutnya 
yaitu perakitan komponen untuk membentuk kursi secara utuh, perakitan komponen dilakukan dengan cara menyambungkan setiap komponen dengan menggunakan perekat epoxy dan diperkuat dengan menambahkan dowel. Berikut proses perakitan dan hasil akhir dari prototype kursi bambu yang telah selesai di rakit:

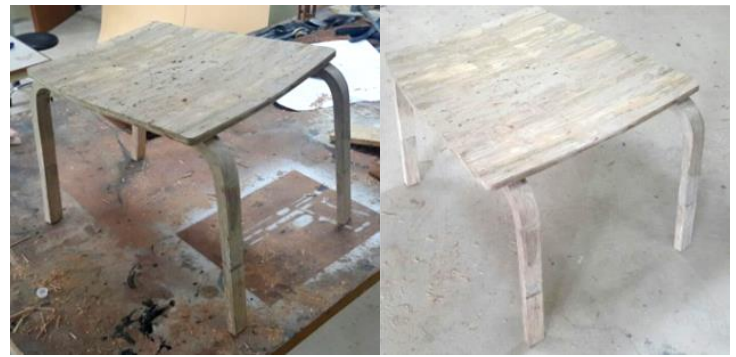

Gambar 14. Hasil perakitan komponen rangka kaki kursi dan komponen alas duduk.

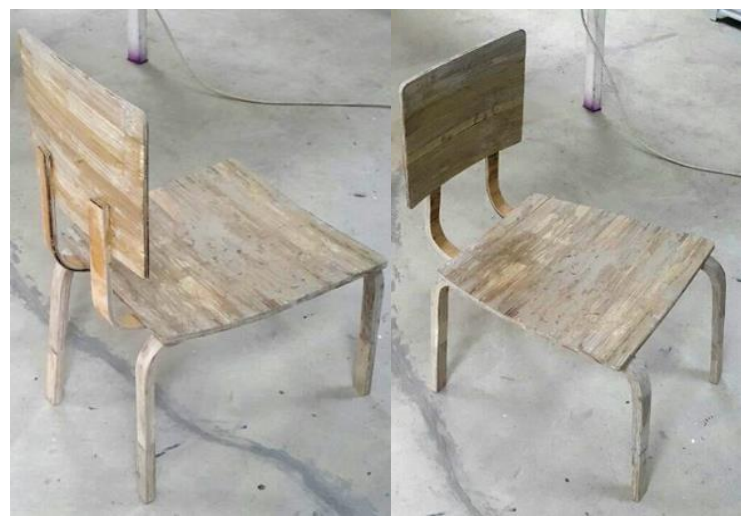

Gambar 15. Prototype kursi bambu laminasi.

\section{Uji Coba Penggunaan Prototype Kursi Bambu Laminasi.}

Untuk menguji aspek ergonomi dan kesesuaian dimensi prototype kursi bambu terhadap aspek antropometri penggunanya, dilakukan uji coba secara langsung kepada pengguna kursi tersebut. Aspek yang akan diujikan kepada pengguna yaitu meliputi kekuatan konstruksi kursi pada saat diduduki oleh pengguna, kenyamanan kursi pada saat digunakan, kesesuaian dimensi kursi terhadap antropometri penggunanya.

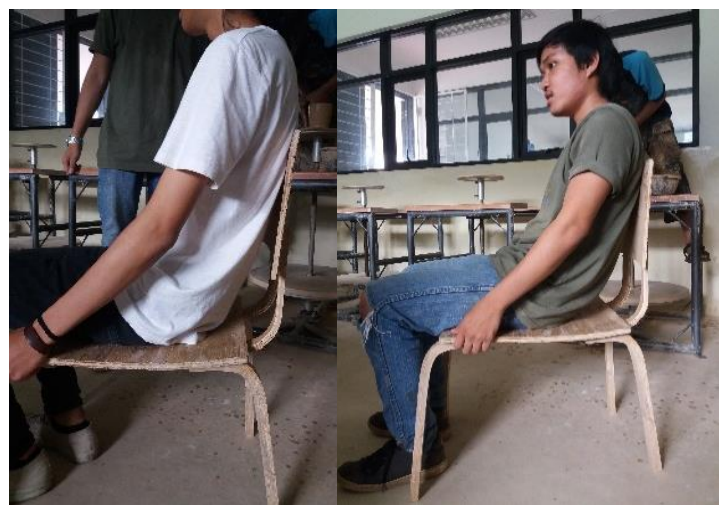

Gambar 16. Uji coba kekuatan struktur rangka dan sandaran kursi dari prototype kursi bambu laminasi.

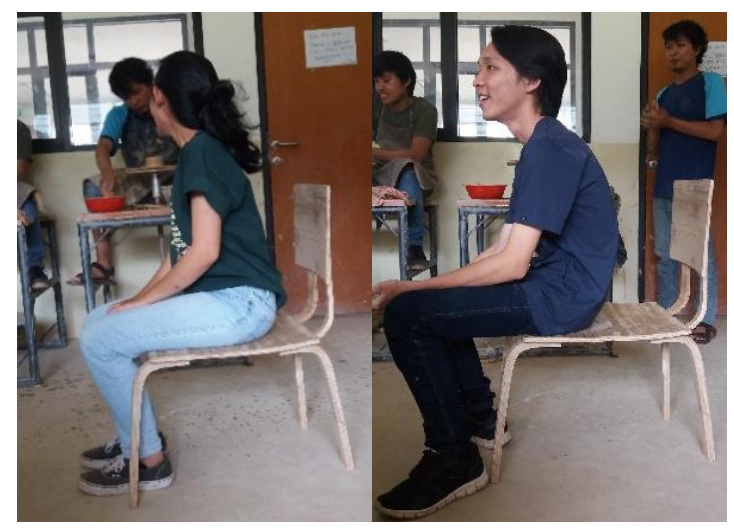

Gambar 17. Uji coba posisi duduk dan kesesuaian antropometri pengguna terhadap dimensi kursi.

Uji coba penggunaan kursi bambu dilakukan oleh 8 orang penguji dengan rentang umur antara 19-20 tahun, berat badan antara $50-90 \mathrm{~kg}$ dan tinggi badan pengguna antara 150-172 $\mathrm{cm}$. Hasil yang didapat dari proses uji coba tersebut, akan dijadikan sebagai bahan pertimbangan untuk melakukan revisi desain prototype kursi bambu laminasi agar sesuai dengan standar ergonomi dan antropometri dari penggunanya.

Berikut hasil respon pengguna pada saat proses uji coba penggunaan prototype kursi bambu laminasi:

a. Aspek struktur rangka kursi:

- Struktur dudukan kursi dan sandaran kursi terlihat ringkih karena memiliki ketebalan kurang dari $3 \mathrm{~cm}$.

- Struktur rangka kursi secara keseluruhan kurang kokoh karena 
masih terasa bergoyang pada saat diduduki.

b. Aspek dimensi kursi dan antropometri pengguna:

- Jarak sandaran kursi terlalu jauh.

- Tinggi sandaran kursi terlalu rendah

c. Aspek ergonomi kursi:

- Sandaran punggung tidak nyaman karena dimensi kurang tinggi.

- Tidak nyaman pada saat bersandar, karena posisi sandaran terlalu jauh dari alas duduk.

Berikut tabel perbandingan data dimensi akhir dari prototype kursi bambu laminasi dan Tabel data antropometri hasil analisa Wignjosoebroto:

Tabel 3. Tabel perbandingan data antropometri prototype kursi bambu laminasi dengan data hasil analisa antropometri Wignjosoebroto

\begin{tabular}{|l|c|c|c|}
\hline Ukuran Dimensi & $\begin{array}{c}\text { Prototype } \\
\text { Kursi Bambu } \\
(\mathrm{cm})\end{array}$ & $\begin{array}{c}\text { data } \\
\text { antropometri } \\
\text { Wignjosoebroto } \\
(\mathrm{cm})\end{array}$ & Ket \\
\hline $\begin{array}{l}\text { Tinggi alas } \\
\text { duduk }\end{array}$ & 39 & 35 & $\begin{array}{c}\text { Tidak } \\
\text { sesuai }\end{array}$ \\
\hline $\begin{array}{l}\text { Lebar alas } \\
\text { duduk }\end{array}$ & 47 & 44 & $\begin{array}{c}\text { Tidak } \\
\text { sesuai }\end{array}$ \\
\hline $\begin{array}{l}\text { Panjang alas } \\
\text { duduk }\end{array}$ & 51 & 45 & $\begin{array}{c}\text { Tidak } \\
\text { sesuai }\end{array}$ \\
\hline $\begin{array}{l}\text { Tinggi } \\
\text { sandaran }\end{array}$ & 30 & 53 & $\begin{array}{c}\text { Tidak } \\
\text { sesuai }\end{array}$ \\
\hline $\begin{array}{l}\text { Lebar sandaran } \\
\text { punggung }\end{array}$ & 40 & 41 & Sesuai \\
\hline $\begin{array}{l}\text { Sudut sandaran } \\
\text { punggung }\end{array}$ & $105^{\circ}$ & $105^{\circ}$ & Sesuai \\
\hline
\end{tabular}

\section{Revisi Desain Prototype Kursi Bambu Laminasi.}

Dari hasil respon pengguna pada saat uji coba kursi bambu laminasi dan hasil perbandingan data antropometri dari analisa Wignjosoebroto, prototype kursi yang telah dibuat, masih belum memenuhi standar antropometri dan ergonomi dari penggunanya.

Agar prototype kursi bambu laminasi dapat memenuhi standar antropometri dan ergonomi, harus dilakukan revisi desain yang meliputi aspek struktur rangka kursi dan dimensi kursi

yang berhubungan dengan antropometri dan ergonomi dari pengguna kursi tersebut.

Tabel 4. Tabel jenis revisi desain dari prototype kursi bambu laminasi.

\begin{tabular}{|c|c|}
\hline Jenis Revisi Desain & \multicolumn{1}{|c|}{ Detail Revisi Desain } \\
\hline struktur rangka kursi & $\begin{array}{l}\text { 1. Menambah ketebalan struktur } \\
\text { rangka menjadi 4cm } \\
\text { 2. Menambah struktur rangka } \\
\text { penguat untuk dudukan dan } \\
\text { sandaran kursi }\end{array}$ \\
\hline $\begin{array}{l}\text { Aspek dimensi kursi, } \\
\text { antropometri dan } \\
\text { ergonomi pengguna }\end{array}$ & $\begin{array}{l}\text { 1. Revisi ukuran kedalaman } \\
\text { dudukan kursi menjadi } 45 \mathrm{~cm}\end{array}$ \\
$\begin{array}{l}\text { 2. Tinggi sandaran duduk menjadi } \\
40 \mathrm{~cm} \text {. Tinggi alas dudukan kursi } 45 \mathrm{~cm}\end{array}$ \\
\hline
\end{tabular}

Berikut hasil revisi desain dan dimensi dari kursi bambu laminasi yang telah disesuaikan dengan hasil analisa data antropometri dari penggunanya:

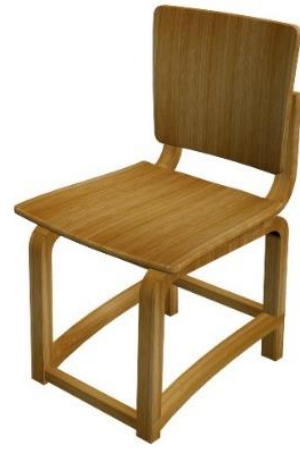

Tampak 3d depan Tampak 3d belakang Gambar 18. Hasil revisi desain kursi bambu laminasi.

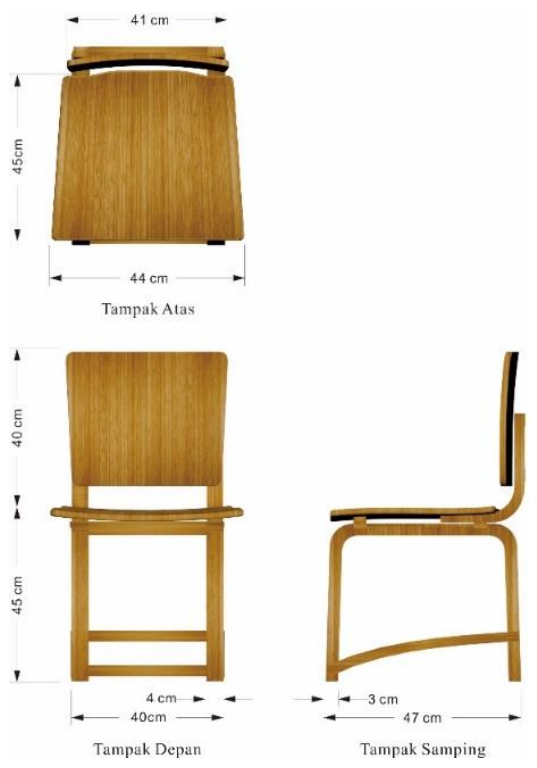

Tampak depan Tampak samping

Gambar 19. Gambar revisi dimensi kursi bambu. 


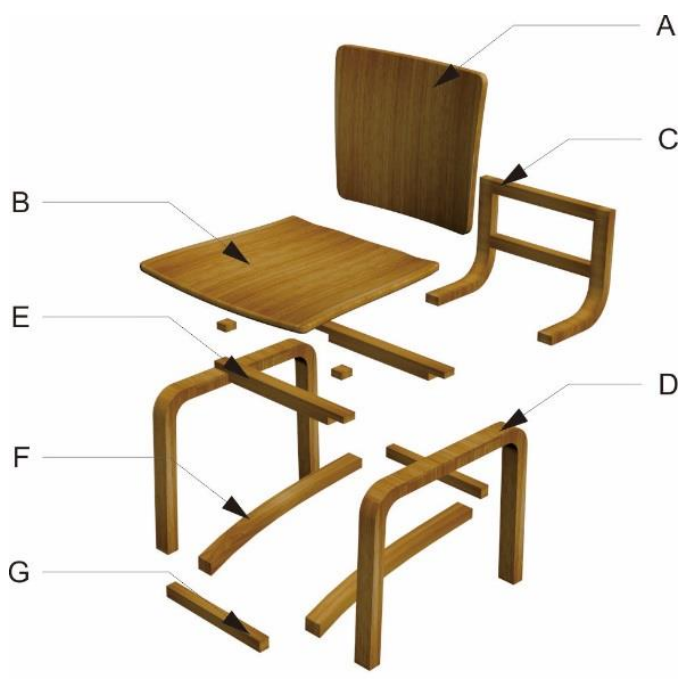

Gambar 20. Gambar uraian komponen kursi bambu.

Berikut informasi keterangan gambar:
A. Komponen sandaran duduk
B. Komponen alas duduk
C. Komponen rangka sandaran duduk
D. Komponen rangka kaki
E. Komponen struktur penahan alas duduk
F. Komponen penguat rangka alas duduk samping
G. Komponen penguat rangka alas duduk depan

\section{KESIMPULAN}

Prototype kursi bambu laminasi yang telah dibuat, belum dapat memenuhi setandar ergonomi dan antropometri dari penggunanya. Untuk memenuhi setandar ergonomi dan antropometri yang ideal, dilakukan revisi desain dari prototype kursi bambu tersebut, yang meliputi:

1. Struktur rangka kursi, meliputi penambah ketebalan struktur rangka menjadi $4 \mathrm{~cm}$, menambah struktur rangka penguat untuk dudukan dan sandaran kursi.

2. Aspek dimensi kursi, antropometri dan ergonomi pengguna, meliputi revisi ukuran kedalaman dudukan kursi, tinggi sandaran duduk dan tinggi alas dudukan kursi.

Acuan data yang digunakan untuk membuat revisi desain dari kursi bambu laminasi yaitu berdasarkan hasil pengujian langsung prototype kursi oleh pengguna dan berdasarkan data hasil analisa pengukuran antropometri untuk kursi bambu yang dilakukan oleh Wignjosoebroto.

Penelitian tahap lanjutan diperlukan untuk menguji hasil revisi desain yang telah dilakukan dan menerapkan hasil revisi tersebut untuk pembuatan prototype dari kursi bambu laminasi.

\section{DAFTAR PUSTAKA}

1. Arya Pr, Denny N. Redesain Kursi Bamboo Bent Lamination Dengan Konsep Design Guidelines Collaborative Framework (Dgls-Cf) Menuju Sustainable Product, Jurnal ilmiah teknik industri, vol 12, no. 1 , Juni 2013.

2. Dassault Systèmes. Student's Guide to Learning SolidWorks Software. SolidWorks Corporation, 1995-2010.

3. Gusti M. Analisis Arah Laminasi Vertikal Dan Horisontal Terhadap Perilaku Lentur Balok Bambu Laminasi. Jurnal SMARTek, 2008, Vol 6, No 2.

4. Hari N. Pengolahan Material Bambu Dengan Menggunakan Teknik Laminasi Dan Bending Untuk Produk Furniture. Jurnal Widyakala, 2014, Vol 1, No 1.

5. Iwan S, Rusli, Dedi K. Standardisasi Bambu Laminasi Sebagai Alternatif Pengganti Kayu Konstruksi. Prosiding Ppi Standardisasi 2009, volume 14.

6. Metric Design Handbook Planning and Design Data 2 nd Ed.edited by D. Adler, Architectural Press.

7. Openshaw S, Taylor E. Ergonomics and Design A Reference Guide. Allsteel Inc, 2009.

8. Robert W, Lang. Essential Techniques for Bending Wood, Popular Woodworking, October 2005.

9. Wignjosoebroto S, Vanany I. Implementasi Quality Function Deployment Pada Perancangan Produk Kursi Tamu Dari Bambu Dengan Mempertimbangkan Antropometri Tubuh Manusia. 
Laboratorium Ergonomi \&

Perancangan Sistem Kerja Jurusan

Teknik Industri ITS, 2007. 